\title{
On three new Euathlus tarantulas from Argentina and cladistic analysis of the genus
}

Nelson Ferretti: Centro de Estudios Parasitológicos y de Vectores CEPAVE (CCT- CONICET- La Plata), Boulevard 120 s/n e/61 y. 62, La Plata, Buenos Aires, and Argentina. E-mail: nferretti@conicet.gov.ar

\begin{abstract}
Three unknown species of Euathlus Ausserer 1875 (Araneae: Theraphosidae) are recognized and formally described. Euathlus diamante Ferretti sp. nov., E. sagei Ferretti sp. nov., and E. tenebrarum Ferretti sp. nov. are described from the Mendoza and Neuquén provinces of western Argentina. The cladistic analysis showed Euathlus as monophyletic supported by the following synapomorphies: i) male tibial apophysis with fused branches bases; ii) presence of a ventral spine on retrolateral branch of male tibial apophysis; iii) sternum longer than wide. According to this cladistics analysis, a tree topology of (Homoeomma uruguayense (Mello-Leitão 1946) (Plesiopelma longisternale (Schiapelli \& Gerschman 1942) (Grammostola anthracina (C.L. Koch 1842) (Phrixotrichus scrofa (Molina 1788) (E. tenebrarum sp. nov. (E. truculentus L. Koch 1875, E. sagei sp. nov. ((E. parvulus (Pocock 1903) (E. condorito Perafán \& Pérez-Miles 2014, E. manicata (Simon 1892), E. atacama Perafán \& Pérez-Miles 2014)) (E. antai Perafán \& Pérez-Miles 2014, E. diamante sp. nov.)))) )))) is reported.
\end{abstract}

Keywords: New species, spider, Theraphosidae, systematics, phylogenetics

Theraphosidae Thorell 1894 is the largest family of mygalomorph spiders with 126 genera and more than 950 species described mainly in tropical and subtropical regions (World Spider Catalog 2014). These spiders show noticeable taxonomic difficulties given their great morphological homogeneity (Raven 1985; Pérez-Miles et al. 1996; Bertani 2000; Perafán \& PérezMiles 2014). An example of that is the genus Euathlus Ausserer 1875 , which has experienced a long and controversial taxonomic history, evidenced by the difficulties of diagnosing and differentiating species (Perafán \& Pérez-Miles 2014).

Euathlus was established on the basis of its type species E. truculentus L. Koch 1875, originally described from Argentina and Chile. Recently, Perafán \& Pérez-Miles (2014) made a taxonomic revision and phylogenetic analysis of the genus Euathlus describing new species and providing a diagnostic key. However, the authors did not examine additional material from Argentina and consequently, only made reference to the original data of E. truculentus (Perafán \& Pérez-Miles 2014).

The genus Euathlus is characterized by possessing only one patch of urticating setae, and those setae consisting of Type III and Type IV urticating setae. Males have a palpal organ with two prolateral keels and tip directed retrolaterally, the tibial apophyses with retrolateral spines, a subapical spine on retrolateral branch and a basal spine on prolateral branch. Females have two spermathecal receptacles with a lateral spheroid chamber (Perafán \& Pérez-Miles 2014). This genus is morphologically similar and phylogenetically related to Phrixotrichus Simon 1889 (Perafán \& Pérez-Miles 2014). To date, Euathlus has six valid species: Euathlus antai Perafán \& Pérez-Miles 2014, E. atacama Perafán \& Pérez-Miles 2014, E. condorito Perafán \& Pérez-Miles 2014, E. manicata (Simon 1892), E. parvulus (Pocock 1903), all distributed in Chile, and E. truculentus L. Koch 1875 from Argentina and Chile.

Investigation of material from the Museo Argentino de Ciencias Naturales "Bernardino Rivadavia" (MACN-Ar) and the Instituto Argentino de Investigaciones de las Zonas Áridas (CAI), along with material recorded in recent survey campaigns (granted by the British Tarantula Society) to the Andean-patagonic forests of south western Argentina
(Neuquén province), led me to describe three new species from western Argentina. Moreover, I present a cladistic analysis of Euathlus building upon the dataset presented by Perafán \& Pérez-Miles (2014) including these new species.

\section{METHODS}

The specimens used in this study are lodged in the following institutions: Instituto Argentino de Investigaciones de las Zonas Áridas, Mendoza, Argentina (CAI); Museo Argentino de Ciencias Naturales "Bernardino Rivadavia", Buenos Aires Argentina (MACN-Ar); Laboratorio de Zoología de Invertebrados II, Universidad Nacional del Sur, Buenos Aires, Argentina (LZI). Specimens were examined using an Olympus SZ stereomicroscope and photographed using a SONY Hx200v camera attached to a stereomicroscope. The following abbreviations are utilized: $\mathrm{ALE}=$ anterior lateral eyes, $\mathrm{AME}=$ anterior median eyes, $\mathrm{BN}=$ basal nodule, $\mathrm{D}=$ dorsal, $\mathrm{P}=$ prolateral, $\mathrm{PB}=$ prolateral branch of tibial apophysis, $\mathrm{PI}=$ prolateral inferior keel, PLE $=$ posterior lateral eyes, PLS $=$ posterior lateral spinnerets, $\mathrm{PME}=$ posterior median eyes, $\mathrm{PMS}=$ posterior median spinnerets, $\mathrm{PS}=$ prolateral superior keel, $\mathrm{R}=$ retrolateral, $\mathrm{RB}=$ retrolateral branch of tibial apophysis. Female genitalia were dissected and cleared in concentrated lactic acid for 60-120 minutes to study the shape of spermathecae. All measurements are given in millimeters and were made with digital dial calipers with an error of $0.01 \mathrm{~mm}$, rounded up to one significant decimal where appropriate and an Olympus stereoscopic microscope equipped with an ocular micrometer scale. Appendage measurements were based on left appendages in the dorsal view. Lengths of leg articles were taken from the mid-proximal point of articulation to the mid-distal point of the article (sensu Coyle (1995) Fig. 1 and Bond (2012) Figs. 11-16). Terminology for tibial apophyses (or spurs) follows the general usage in Theraphosidae. It includes the prolateral apophysis (or apophysis branch) and retrolateral apophysis (e.g., Bertani 2001; Pérez-Miles et al. 2008). Spine notation follows Petrunkevitch (1925). Male palpal bulb keels terminology follows Bertani (2000). Urticating setae terminology follows Cooke et al. (1972). 


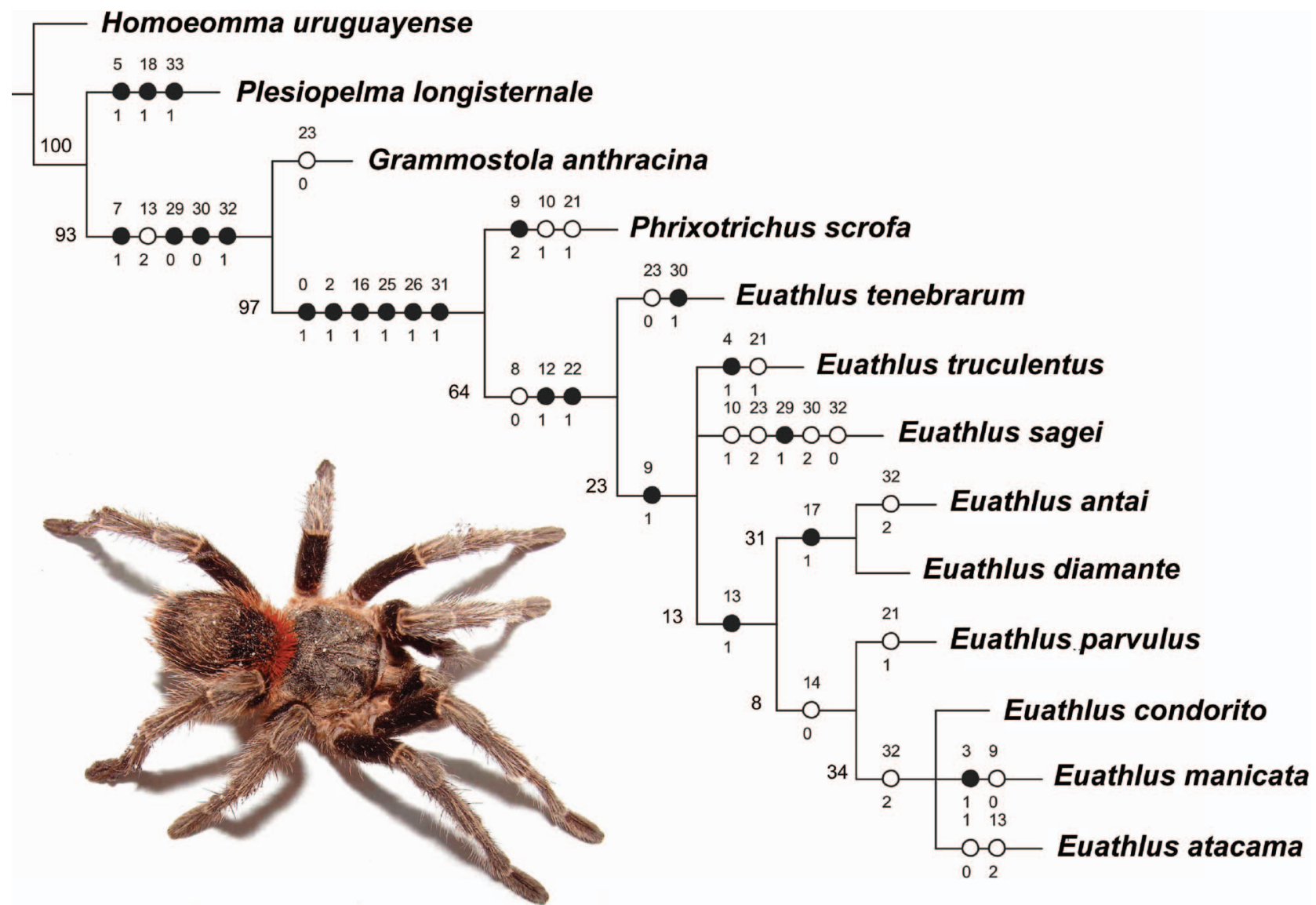

Figure 1.-Hypothetical Euathlus phylogenetic relationships. One tree using implicit enumeration (Length $=59 ; \mathrm{CI}=0.71 ; \mathrm{RI}=0.66$ ). White and black circles imply homoplastic and non-homoplastic characters that define each node, respectively. The numbers at each node are the frequency differences (GC) jackknife values.

Cladistic analysis built upon the data matrix from PérezMiles \& Perafán (2014). - I scored the newly described species (Euathlus diamante sp. nov., Euathlus sagei sp. nov. and Euathlus tenebrarum sp. nov.) for 34 characters (Table 1) obtained from Perafán \& Pérez-Miles (2014), removing invariant characters. The ingroup comprised nine taxa: Euathlus antai, E. atacama, E. condorito, E. diamante sp. nov., E. manicata, E. parvulus, E. sagei sp. nov., E. tenebrarum sp. nov., and E. truculentus. The outgroup used and their character scores were taken from Perafán \& Pérez-Miles (2014). The outgroup included the following species: Homoeomma uruguayense (Mello-Leitão 1946); Grammostola anthracina (C.L. Koch 1842); Phrixotrichus scrofa (Molina 1788); and Plesiopelma longisternale (Schiapelli \& Gerschman 1942). The tree was rooted using $H$. uruguayense. The data matrix was constructed using Nexus Data Editor version 0.5.0 software (Page 2001). Parameters used in this study followed Perafán \& Pérez-Miles (2014), allowing a more explicitly comparison of results between the two studies. For that purpose, the cladistic analysis was carried out with the program TNT version 1.1 (Goloboff et al. 2003a), using the implicit enumeration algorithm. Implied weighting (Goloboff 1993) was used with concavity indices (k) ranging from 1 to 6. Jacknife (Goloboff et al. 2003b) values were calculated for each node using resampled matrices, with 1000 pseudoreplicates and $36 \%$ as the probability of alteration.
Characters scored taken from Perafán \& Pérez-Miles (2014).-Multistate characters were coded as non-additive. The data matrix is listed in Table 1. (0) Embolus direction: directed ventrolaterally $=0$; directed retrolaterally $=1$. (1) Relative width of bulb sclerites II + III: wide $=0$; narrow (less than $10 \%$ of length) $=1$. (2) Position of distal PI: prolateral = 0 ; prolateroventral $=1$. (3) Apical keel: absent $=0$; present $=$ 1. (4) Ventral crest on PI: absent $=0$; present $=1$. (5) Subapical tooth on PI: absent $=0$; present $=1$. (6) Tegular apophysis on bulb: absent $=0$; present $=1$. (7) Position of male tibial apophysis: ventral $=0$; prolateroventral $=1$. (8) Male tibial apophysis: branches with fused bases: 0 , branches with non-fused bases: 1. (9) Male tibial apophysis: with one retrolateral spine $=0$; with two retrolateral spines $=1$; without retrolateral spines $=2$. (10) $\mathrm{PB}$ : with basal spine $=0$; without basal spine $=1$. (11) Position of distal spine on RB: subapical $=0$; apical $=1$. (12) Ventral spine on RB: absent $=0$; present $=1$. (13) Flexion of male metatarsus I: between the branches of tibial apophysis $=0$; on the apex to the retrolateral branch $=1$; retrolateral to the tibial apophysis $=2$. (14) Male metatarsus I: strongly curved $=0$; straight $=1$. (15) Spermathecal morphology: spheroid shape $=0$; not spheroid shape $=1$. (16) Spermathecae with a lateral spheroid chamber: absent $=0$; present $=1$. (17) Spermathecal receptacles: single $=0$; bifurcated $=1$. (18) Spermathecal neck: straight $=0 ;$ spiralled $=1$. (19) Digitiform projections 
on spermathecae: absent $=0$; present $=1$. (20) Female palpal tibia spination: with apical spines only $=0$; with apical and others ventral spines $=1$. (21) Labial cuspules: numerous $(>20)=0$; few or none $=1$. (22) Sternum: as long as wide $=0$; longer than wide $=1$. (23) Extension of scopula on metatarsus I: complete $=0$; more than a half $($ distal $2 / 3)=1$; distal half $=2$. (24) Extension of scopula on metatarsus II: more than half $($ distal 2/3) $=0$; distal half $=1$. (25) Extension of scopula on metatarsus III: distal half $=0$; less than half $(1 / 3)=1$; only apical $(1 / 4,1 / 5)=2$. (26) Extension of scopula on metatarsus IV: less than half $(1 / 3)=0$; only apical $(1 / 4,1 / 5)=1$; absent $=2$. (27) Scopulae on tarsi I: entire $=0$; widely divided $=1$. (28) Scopulae on tarsi II: entire $=0$; narrowly divided $=1$; widely divided $=2$. (29) Scopulae on tarsi III: entire $=0$; narrowly divided $=1$; widely divided $=2$. (30) Scopulae on tarsi IV: entire $=0$; narrowly divided $=1$; widely divided $=2$. (31) Tarsal claws: with teeth $=0$; without teeth $=1$. (32) Length of urticating setae type III: short (less than 0.75 of the optical field diameter of microscope; $40 \times)=0$; mediumsized (more than 0.75 and less than 1.5 of the optical field diameter, $40 \times)=1$; long (more than 1.5 of the optical field diameter, $40 \times)=2$. (33) Barbs on urticating setae type III: $\operatorname{long}=0$; short $=1$.

The data matrix obtained from Perafán \& Pérez-Miles (2014) comprises 8 continuous quantitative characters and 25 discrete characters. The use of continuous characters has been questioned and may be inappropriate for phylogenetic reconstruction (Hendrixson \& Bond 2009). Hendrixson \& Bond (2009) indicated that due caution should be exercised before employing this character type mainly in the absence of other independently derived source of characters. Unfortunately, lacking discrete characters is a ubiquitous phenomenon found across the Mygalomorphae, a lineage morphologically homogeneous that clearly lacks rich sources of discrete characters (Hendrixson \& Bond 2009). Also, a number of methods for handling these continuous data exist (García-Cruz \& Sosa 2006), all with different implications for inferring accurate phylogenies. However, Goloboff et al. (2006) suggested using implied weights (Goloboff 1993), a method implemented in the present work.

\section{PHYLOGENETICS}

The phylogenetic analysis using implied weighting and implicit enumeration resulted in a single tree (Fig. 1) with $\mathrm{K}$ values from 1 to 6 (59 steps, $\mathrm{CI}=0.71, \mathrm{RI}=0.66)$. The genus Euathlus is monophyletic including the new species, supported by the following synapomorphies: male tibial apophysis with fused branches bases (Figs. 2e, 4f, 7e); presence of a ventral spine on retrolateral branch of male tibial apophysis (Figs. 2e, 4f, 7e) and sternum longer than wide (Figs. 2d, 4d, 7d). Euathlus tenebrarum sp. nov., characterized by having a complete extension of scopula on metatarsus I and narrowly divided on tarsi IV, was shown to be the sister group to the remaining species by the presence of one retrolateral spine on male tibial apophysis. Euathlus truculentus is the sister species to the group of $E$. antai, E. diamante sp. nov., E. parvulus, $E$. condorito, E. manicata and E. atacama supported by the flexion of male metatarsus I on the apex to the retrolateral branch. The position of E. sagei sp. nov. was unresolved. The monophyletic group of $E$. diamante sp. nov. and $E$. antai 


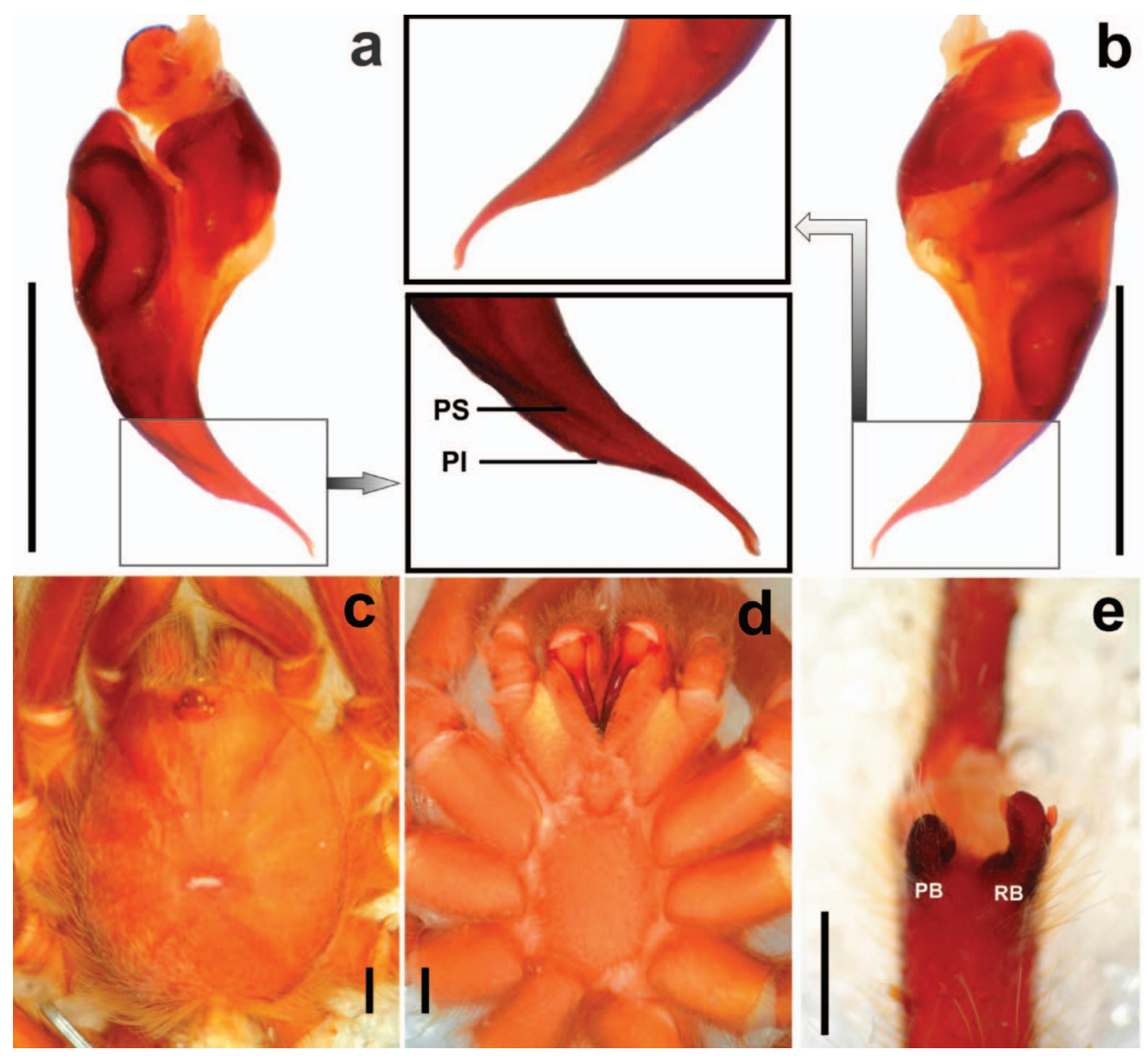

Figure 2.-Euathlus diamante sp. nov. male holotype (CAI 3330). a. Palpal organ, prolateral view, the box indicates the apical embolus with keels; b. palpal organ, retrolateral view, the box indicates the apical embolus; c. carapace, dorsal view; d. sternum, ventral view; e. tibial apophysis, ventral view. PS $=$ prolateral superior keel, $\mathrm{PI}=$ prolateral inferior keel, $\mathrm{PB}=$ prolateral branch, $\mathrm{RB}=$ retrolateral branch. Scale bar $=1 \mathrm{~mm}$.

is supported by the bifurcated spermathecal receptacles (Fig. 3e). Euathlus parvulus is the sister group of E. condorito, E. manicata and E. atacama, which are together supported by the strongly curved male metatarsus. There were no synapomorphies that resolve the internal relationships within the parvulus group, but their monophyly is supported by possession of long urticating setae type III. Perafán \& PérezMiles (2014) reported on the monophyly of the genus Euathlus, and with the inclusion of these new species, the genus continues to be well supported. Euathlus truculentus was the sister species of the all remaining Euathlus (Perafán \& Pérez-Miles 2014), but in the present work, Euathlus tenebrarum sp. nov. is determined to be the sister lineage to all other Euathlus. The position of Euathlus parvulus is similar to that found by Perafán \& Pérez-Miles (2014). Moreover, E. antai was found to be the sister species of $E$. diamante sp. nov., a relationship unresolved in the phylogeny proposed by Perafán \& Pérez-Miles (2014).

\section{TAXONOMY}

Family Theraphosidae Thorell 1870

\section{Genus Euathlus Ausserer 1875 \\ Euathlus diamante new species \\ Figs. $2 \& 3$, Tables $2 \& 3$}

Type material.-Male holotype: ARGENTINA: Mendoza: San Carlos department, Reserva Laguna de Diamante, Alvarado $\left(34.2439^{\circ} \mathrm{S}, 69.3778^{\circ} \mathrm{W}\right)$, elevation $2297 \mathrm{~m}$, 5-8 January 2006, S. Roig \& G. Debandi (CAI 3330). Female paratype: ARGENTINA: Mendoza: San Carlos department, Reserva Laguna de Diamante, Alvarado $\left(34.2350^{\circ} \mathrm{S}, 69.3833^{\circ} \mathrm{W}\right)$, elevation 2347 m, 13-23 February 2006, S. Claver \& R. Carrara (CAI 3317).

Etymology.-The name refers to the Diamante Volcano in Mendoza, Argentina, where this species was found.

Diagnosis.-Male of this species can be distinguished by the non-convergent branches of the tibial apophysis (Fig. 2e) together with a prolateral keel wide and entire on male palpal bulb (Fig. 2a). Female differs from the other species by the shape of the spermathecae with two seminal receptacles bifurcated. Female spermathecae resembles E. antai (Perafán \& Pérez-Miles, fig. 3a) but differs by the less developed internal receptacle and by the oval chambers (Fig. 3e). This species is 


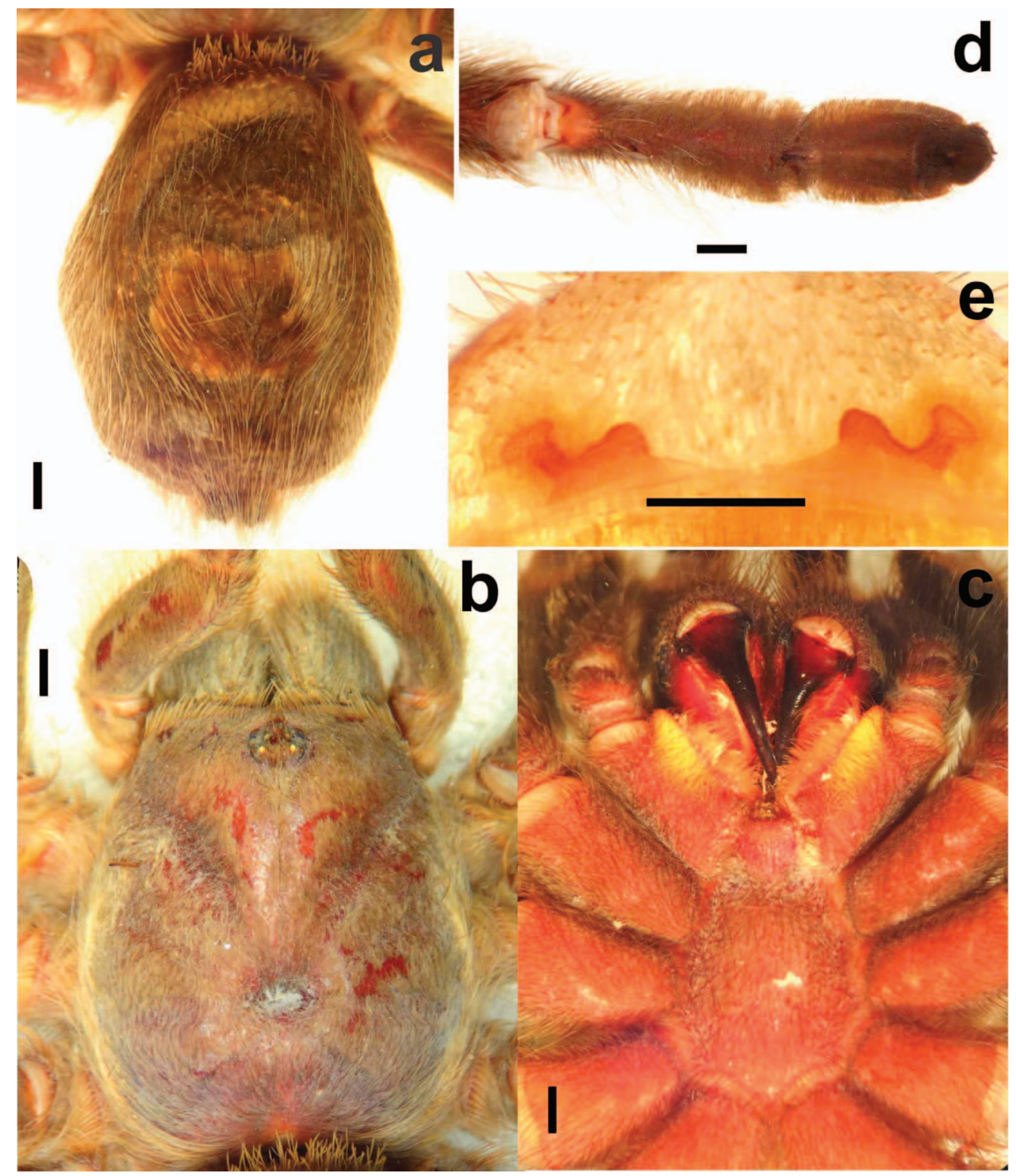

Figure 3.-Euathlus diamante sp. nov. female paratype (CAI 3317). a. Abdomen, dorsal view; b. carapace, dorsal view; c. sternum, ventral view; d. tarsus I, ventral view; e. spermathecae, dorsal view. Scale bar $=1 \mathrm{~mm}$.

characterized as inhabiting the Argentinean extra-Andean System with its reproductive period occurring in summer.

Description.-Male holotype (CAI 3330). Color (in alcohol): Cephalothorax and legs light brown (Fig. 2c, d). Abdomen lost. Carapace length 11.1, width 10.2. Anterior eye row slightly procurved, posterior highly recurved. Eyes sizes and interdistances: AME 0.18, ALE 0.14, PME 0.09, PLE 0.15, AME-AME 0.26, AME-ALE 0.10, PME-PME 0.53, PME-PLE 0.05, ALE-PLE 0.11, OQ length 0.9, width 1.2 , clypeus 0.4 . Fovea transverse, straight, width 1.4. Labium length 0.9 , width 1.6 with 102 cuspules. Maxillae (right/left) with 129/134 cuspules. Sternum length 4.5, width 2.7 (Fig. 2d). Chelicerae with six well-developed teeth on promargin of furrow. Tarsi I-IV densely scopulate and entire. Metatarsi I 1/3 scopulate, II 1/2 scopulate, III 1/3, IV 1/4 apically scopulate. Leg and palpal segments lengths in Table 2. Spination: Femora of palp and legs I and IV, 0; II 1-1-1 P, 1 R; III 1-1 R, 1 P. Patellae: palp 1 P; I 1 V, 1-1 R; II, III and IV, 0. Tibiae: palp 2-2 V, 1-1 R; I 2-2 V, 2-1 R, 1-1-1 P; II 2-2-2 V, 1-1-1 R; III 2-2-2 V, 2-1-1-2 P, 2-2-1-2 R; IV 2-1-2-2 V, 1-1-2-2 P, 1-1-1-1-2 R. Metatarsi: I 1 V; II 1-1-1 V; III 2-2-2 V, 1-1-2 R, 2-2-2 P; IV 1-2-2 V, 1-1-1 P, 1-1-1 R. Tarsi I-IV, 0. Metatarsus I straight. Tibia I with retrolateral branch noticeably longer than prolateral; PB with a basal internal short spine, RB with an external and one internal subapical spine (Fig. 2e). Flexion of metatarsus I on the RB. Palpal organ with unequal prolateral keels, well-developed PS, and wide PI with small teeth on the curvature of the embolus (Fig. 2a, b).

Female paratype (CAI 3317). Color (in alcohol): Carapace and legs brownish with patellar lines evident, abdomen brown (Fig. 3a, b). Brown setae on body mixed with golden setae. Total length, not including chelicerae, nor spinnerets, 34. 
Table 2.-Euathlus diamante sp. nov., length of leg and palpal segments of male.

\begin{tabular}{lrrrrc}
\hline & I & II & III & IV & Palp \\
\hline Femur & 9.9 & 9.6 & 10.2 & 9.0 & 6.0 \\
Patella & 5.4 & 5.0 & 5.1 & 4.7 & 4.1 \\
Tibia & 8.0 & 7.7 & 7.5 & 7.1 & 5.1 \\
Metatarsus & 7.8 & 7.2 & 6.5 & 8.0 & - \\
Tarsus & 5.8 & 6.2 & 5.3 & 6.1 & 2.2 \\
Total & 36.9 & 35.7 & 34.6 & 34.9 & 17.4 \\
\hline
\end{tabular}

Carapace length, 15.5, width 13.4. Anterior eye row procurved, posterior recurved. Eyes sizes and interdistances: AME 0.21, ALE 0.26, PME 0.20, PLE 0.21, AME-AME 0.46, AME-ALE 0.22, PME-PME 0.77, PME-PLE 0.10, ALEPLE 0.20, OQ length 1.2, width 1.7, clypeus 0.7. Fovea transverse, straight, width 2.1. Labium length 2.1, width 1.9 with 147 cuspules. Maxillae (right/left) with 142/139 cuspules. Sternum length 6.8, width 4.6 (Fig. 3c). Chelicerae with eight well-developed teeth on promargin of furrow and five small teeth on the proximal area of furrow. Tarsi I-IV densely scopulate and entire (Fig. 3d). Metatarsi I fully scopulate, II 1/2 scopulate, III 1/3, IV 1/4 apically scopulate. Leg and palpal segments lengths in Table 3. Spination: Femora I-IV, patellae of palp and legs I-IV and tarsi I-IV 0. Tibiae: palp 1-2 V, 1-2 P; I 1-3 V, 1 P; II 1-2 V, 1-1 P; III 1-2 V, 1-1 P, 2-2-1 R; IV 1-2 V, 1-1-1 P, 1-1-1 R. Metatarsi: I 1-1 V; II 1-1 V; III 1-1-2 V, 1-1-1 R, 1-2-1 P; IV 1-2 V, 1-1-1 R, 1-1-1 P. Type III and IV urticating setae present. PMS well-developed, PLS normal, apical segment digitiform. Spermathecae with two bifurcated seminal receptacles with lateral oval chamber (Fig. 3e).

Distribution and natural history.-Known from central western Mendoza province, Argentina, at the Andean foothills (Fig. 10). Euathlus diamante sp. nov. was found in the Diamante Volcano. The habitat is a high altitude grassland (elevation of about $2200 \mathrm{~m}$ ), charcterized mainly by Poa ligularis Nees ex Steud. (Poaceae) and Stipa speciosa Trin. \& Rupr. (Poaceae) (Roig et al. 1998). This volcano is located the middle of the Patagonia biogeographical province, on shrubland steppes on sandy floors, with Neosparton aphyllum (Gillies \& Hook.) Kuntze (1898) (Verbenaceae) alternating with dune vegetation dominated by Sporobolus rigens E. Desv. (Poaceae). The mean annual temperatures are about $10^{\circ} \mathrm{C}$, and mean annual precipitation of $300 \mathrm{~mm}$ (Páez et al. 2004). The adult male sampled was caught using pitfall traps (presumably walking) during January (summer in southern hemisphere) and the female, also captured with

Table 3.-Euathlus diamante sp. nov., length of leg and palpal segments of female.

\begin{tabular}{lrcrrc}
\hline & I & II & III & IV & Palp \\
\hline Femur & 10.7 & 9.8 & 9.2 & 11.5 & 7.3 \\
Patella & 7.0 & 6.0 & 5.0 & 5.5 & 4.4 \\
Tibia & 7.9 & 6.7 & 6.5 & 7.2 & 6.0 \\
Metatarsus & 6.3 & 6.9 & 6.7 & 9.7 & - \\
Tarsus & 4.4 & 4.5 & 4.3 & 5.7 & 4.6 \\
Total & 36.3 & 33.9 & 31.7 & 39.6 & 22.3 \\
\hline
\end{tabular}

Table 4.-Euathlus sagei sp. nov., length of leg and palpal segments of male.

\begin{tabular}{lrrrrr}
\hline & I & II & III & IV & Palp \\
\hline Femur & 10.1 & 9.9 & 9.0 & 11.0 & 6.2 \\
Patella & 5.3 & 5.6 & 5.4 & 6.1 & 4.2 \\
Tibia & 7.4 & 7.8 & 7.0 & 7.9 & 5.8 \\
Metatarsus & 7.3 & 7.4 & 8.3 & 9.4 & - \\
Tarsus & 5.3 & 5.2 & 4.9 & 5.5 & 2.8 \\
Total & 35.4 & 35.9 & 34.6 & 39.9 & 19.0 \\
\hline
\end{tabular}

pitfall trap was active during the same season (February), thus $E$. diamante sp. nov. is most likely a summer breeding species.

\section{Euathlus sagei new species}

Figs. 4-6, Tables 4 \& 5

Type material.-Male holotype: ARGENTINA: Neuquén: Zapala department, Parque Nacional Laguna Blanca, approximately 300 meters southwest of Atiñir lake, elevation 1360 m, 27 February 2009, R. Sage (MACN-Ar 32685). Female paratype: ARGENTINA: Neuquén: near Zapala city $\left(39.0233^{\circ} \mathrm{S}, 70.0208^{\circ} \mathrm{W}\right)$, elevation $979 \mathrm{~m}, 30$ October 2011, N. Ferretti (MACN-Ar 32686).

Additional material examined.-ARGENTINA: Neuquén: Zapala department, near Zapala city $\left(39.0561^{\circ} \mathrm{S}, 70.3469^{\circ} \mathrm{W}\right)$, elevation $1185 \mathrm{~m}, 30$ October 2011, N. Ferretti (LZI 344), 1 juvenile; Zapala department, near Zapala city $\left(39.0782^{\circ} \mathrm{S}\right.$, $70.5466^{\circ} \mathrm{W}$ ), elevation $1345 \mathrm{~m}, 30$ October 2011, N. Ferretti (LZI 345), 1 juvenile.

Etymology.-This species is a patronym, named in honor of the naturalist Richard D. Sage from the Sociedad Naturalista Andino Patagónica (SNAP), who has collected and kindly donated a specimen belonging to this new species.

Diagnosis.-Male differs from the other Euathlus species by the PI evidently truncated in the embolus (Fig. 4a) in combination with a serrated tip (Fig. 4b). Female differs from other Euathlus species by the shape of the spermathecae with long basis and parallel to epigastric furrow (Fig. 5e) and scopulae divided on tarsi III and IV (Fig. 5d). This species is characterized as inhabiting the patagonic steepe with the reproductive period occurring in summer.

Description.--Male holotype (MACN-Ar 32685). Color (in alcohol): Cephalothorax reddish brown with light grey small setae and golden long setae on margins; abdomen with long brown setae and a patch of red setae on the anterior-dorsal face; sternum, coxa and trochanter reddish (Fig. 4c, e). Total length, not including chelicerae, nor spinnerets, 26.2. Carapace

Table 5.-Euathlus sagei sp. nov., length of leg and palpal segments of female.

\begin{tabular}{lrrrrr}
\hline & I & II & III & IV & Palp \\
\hline Femur & 6.5 & 6.0 & 5.9 & 6.0 & 5.2 \\
Patella & 2.5 & 3.1 & 2.5 & 3.7 & 2.7 \\
Tibia & 5.1 & 4.0 & 4.1 & 5.1 & 3.7 \\
Metatarsus & 3.1 & 3.0 & 3.4 & 4.8 & - \\
Tarsus & 2.5 & 2.9 & 3.0 & 3.7 & 3.1 \\
Total & 19.7 & 19.0 & 18.9 & 22.6 & 14.7 \\
\hline
\end{tabular}




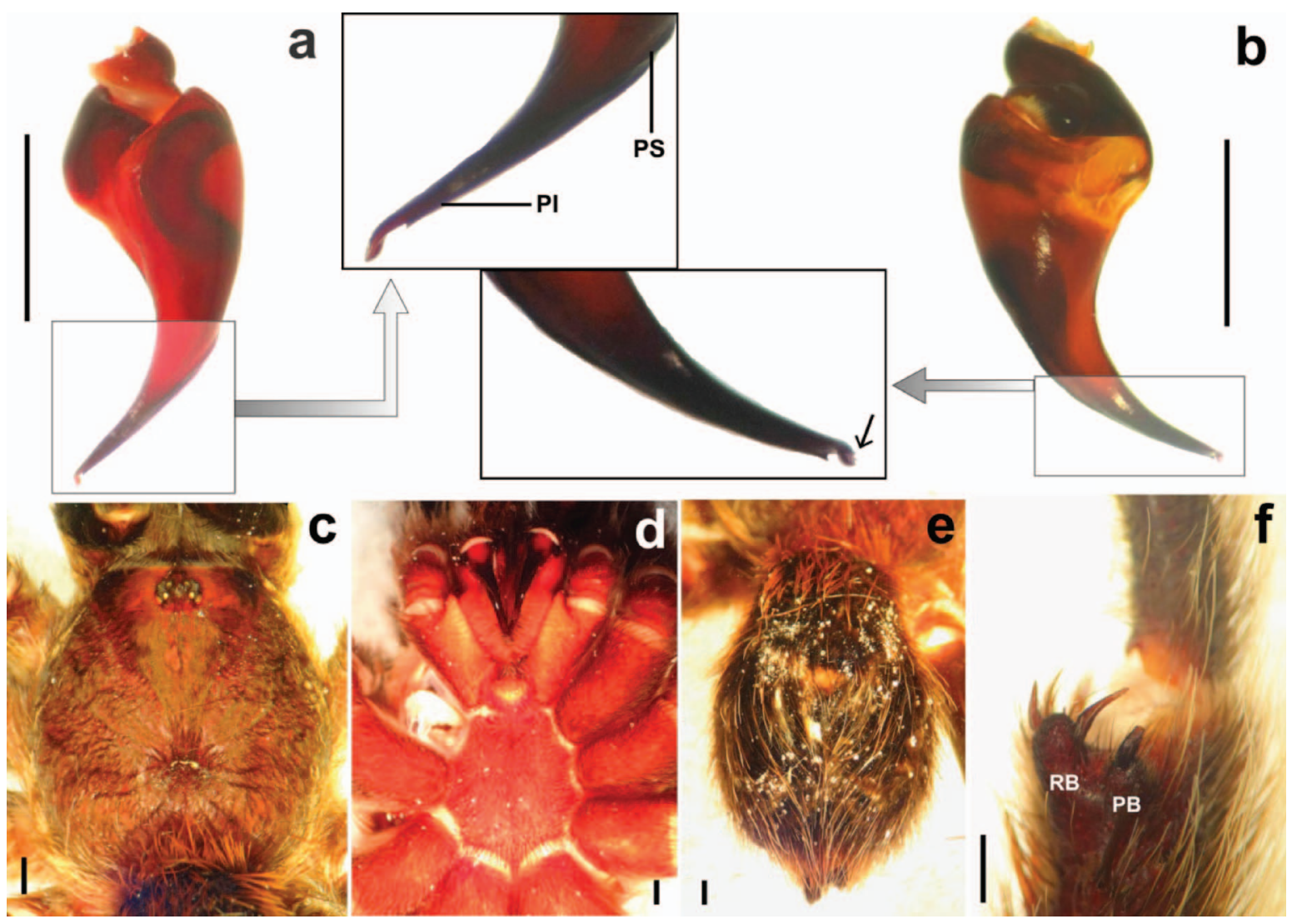

Figure 4.-Euathlus sagei sp. nov. male holotype (MACN-Ar 32685). a. Palpal organ, prolateral view, the box indicates the apical embolus with keels; b. palpal organ, retrolateral view, the arrow inside the box indicates the serrated apical embolus; c. carapace, dorsal view; d. sternum, ventral view; e. abdomen, dorsal view; f. tibial apophysis, ventral view. PS = prolateral superior keel, PI $=$ prolateral inferior keel, PB $=$ prolateral branch, $\mathrm{RB}=$ retrolateral branch. Scale bar $=1 \mathrm{~mm}$.

length 12.6, width 11.5. Anterior eye row procurved, posterior recurved. Eyes sizes and interdistances: AME 0.19, ALE 0.20, PME 0.18, PLE 0.21, AME-AME 0.45, AME-ALE 0.27, PME-PME 0.75, PME-PLE 0.11, ALE-PLE 0.19, OQ length 1.2 , width 1.6 , clypeus 0.3 . Fovea transverse, slightly recurved, width 1.2. Labium length 1.2 , width 1.4 with 79 cuspules. Maxillae (right/left) with 121/125 cuspules. Sternum length 5.8, width 4.5 (Fig. 4d). Chelicerae with six well-developed teeth on promargin of furrow and five small teeth on retromargin. Tarsi I-IV densely scopulate and entire. Metatarsi I fully scopulate, II 2/3 scopulate, III 1/2, IV 1/4 apically scopulate. Leg and palpal segments lengths in Table 4. Spination: Femora of palp and legs I-IV, 0. Patellae: palp 1 P; I 1 V, 1 R; II 1-1 P; III and IV, 0. Tibiae: palp 1-2-1 P, 1-1 V; I 1-1-2-1-1-2 V, 1-1 R, 1-1 P; II 2-1-2-1-2 V, 1-1-1 R, 2-1-1-1 P; III 1-1-2 V, 1-1-1 P, 1-1 R; IV 1-1-2 V, $1 \mathrm{P}, 1-1-1 \mathrm{R}$. Metatarsi: I 1 V; II 1-1 V; III 1-1-1 V, 1-1-1 R, 1-1 P; IV 2-1-11-2 V, 1-1 P, 1-1-1-2 R. Tarsi I-IV, 0. Metatarsus I slightly curved. Tibia I with retrolateral branch longer than prolateral; $\mathrm{PB}$ with an apical strong spine, $\mathrm{RB}$ with an internal and external subapical strong and long spines (Fig. 4f). Flexion of metatarsus I retrolateral to the tibial apophysis. Type III urticating setae present. PMS well-developed, PLS normal, apical segment digitiform. Palpal organ with flat and subequal less developed prolateral keels and serrated tip of embolus; flat
PS long and closer to PI, and PI evidently truncated in the apical third of the embolus (Fig. 4a, b).

Female paratype (MACN-Ar 32686). Color (alive specimem): Cephalothorax reddish brown with light grey small setae and golden long setae on margins; abdomen with long brown setae and a patch of red setae on anterior-dorsal face; sternum, coxa and trochanter reddish with orange setae around spinnerets (Figs. 5a, b; 6a-c). Total length, not including chelicerae, nor spinnerets, 21.6. Carapace length, 8.1, width 7.0. Anterior eye row procurved, posterior recurved. Eyes sizes and interdistances: AME 0.17, ALE 0.16, PME 0.12, PLE 0.12, AME-AME 0.34, AME-ALE 0.09, PME-PME 0.63, PME-PLE 0.06, ALE-PLE 0.10, OQ length 0.9, width 1.3, clypeus 0.2 . Fovea transverse, straight, width 0.8 . Labium length 1.2 , width 1.1 with 47 cuspules. Maxillae (right/left) with 108/111cuspules. Sternum length 3.4, width 2.8 (Fig. 5c). Chelicerae with seven well-developed teeth on promargin of furrow and eight small teeth on the proximal area of furrow. Tarsi I-II densely scopulate and entire, tarsus III fully scopulate divided by a paired setal row and IV fully scopulate divided by a four setal row (Fig. 5d). Metatarsi I and II 1/2 scopulate and entire, III $1 / 3$ and divided by a row of single seta, IV 1/4 apically scopulate and divided by a row of paired setae. Leg and palpal segments lengths in Table 5. Spination: Femora III-IV, patellae of palp and legs I-IV and tarsi I-IV 0. Femur: palp 1 D; I 1 P; II 1 P. Tibiae: palp 1-1-2 V, 1-1 P, 1 R; 


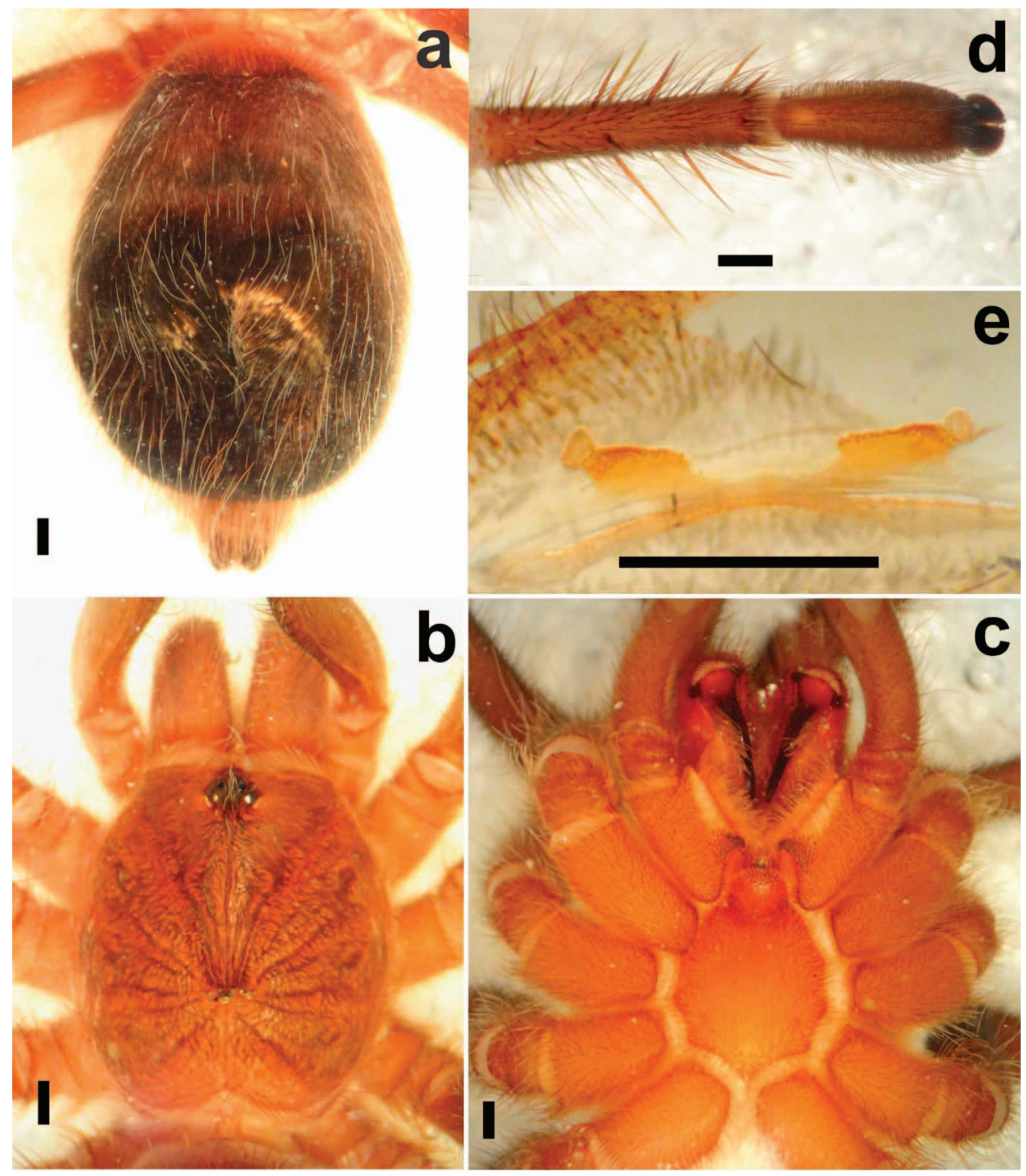

Figure 5.-Euathlus sagei sp. nov. female paratype (MACN-Ar 32686). a. Abdomen, dorsal view; b. carapace, dorsal view; c. sternum, ventral view; d. tarsus IV, ventral view; e. spermathecae, dorsal view. Scale bar $=1 \mathrm{~mm}$.

I 1 V; II 1-1 V; III 1-1-2 V, 1-2-1 P; IV 1-1-2 V, 1 P. Metatarsi: I 1-1 V; II 1-1 V; III 2-2-2 V, 1-1 P, 1-1-1 R; IV 2-2-1-2 V, 1-1 P, 1-2-1 R. Type III and IV urticating setae present. PMS welldeveloped, PLS normal, apical segment digitiform. Spermathecae with two wide and right-angled seminal receptacles each with a lateral rounded chamber pointing laterally (Fig. 5e).

Distribution and natural history.-Known from central Neuquén province, Argentina (Fig. 10). Euathlus sagei sp. nov. inhabits small crevices and short burrows under stones at the patagonic steppe. The habitat where this species was located comprises hilly areas of about 1100 and 1400 meters above sea level (m.a.s.l) and shrubby plateau (Fig. 6d). Some of the characteristic vegetation was Jarava speciosa (Trin. \& Rupr.) (Poaceae), Nassauvia glomerulosa (Lag. ex Lindl.) D. Don (Asteraceae), Mulinum spinosum (Cav.) Pers. (Apiaceae), Senecio bracteolatus Hook \& Arn. (Asteraceae), Bromus tectorum L. (Poaceae) and Poa lanuginosa (Poir.) (Poaceae) (Villamil \& Testoni 2012). The mean minimum temperature is $1.7^{\circ} \mathrm{C}$ (July) and the mean maximum is $16^{\circ} \mathrm{C}$ (January) with a mean annual temperature of approximately $9^{\circ} \mathrm{C}$. The mean annual precipitation is about $200-250 \mathrm{~mm}$. Winds are of high frequencies and speed $(150 \mathrm{~km} / \mathrm{h})$ through the year, predominately from the west (Gandullo et al. 2011). The adult male was captured walking during February (summer in southern hemisphere), thus the reproductive period seems to occur at this time.

\section{Euathlus tenebrarum new species}

Figs. 7-9, Tables 6 \& 7

Type material.-Male holotype: ARGENTINA: Neuquén: Huiliches department, next to Curruhué Chico lake (39.9078 S, 71.3328 W), elevation 1042 m, 28 October 2011, L. Schwerdt 


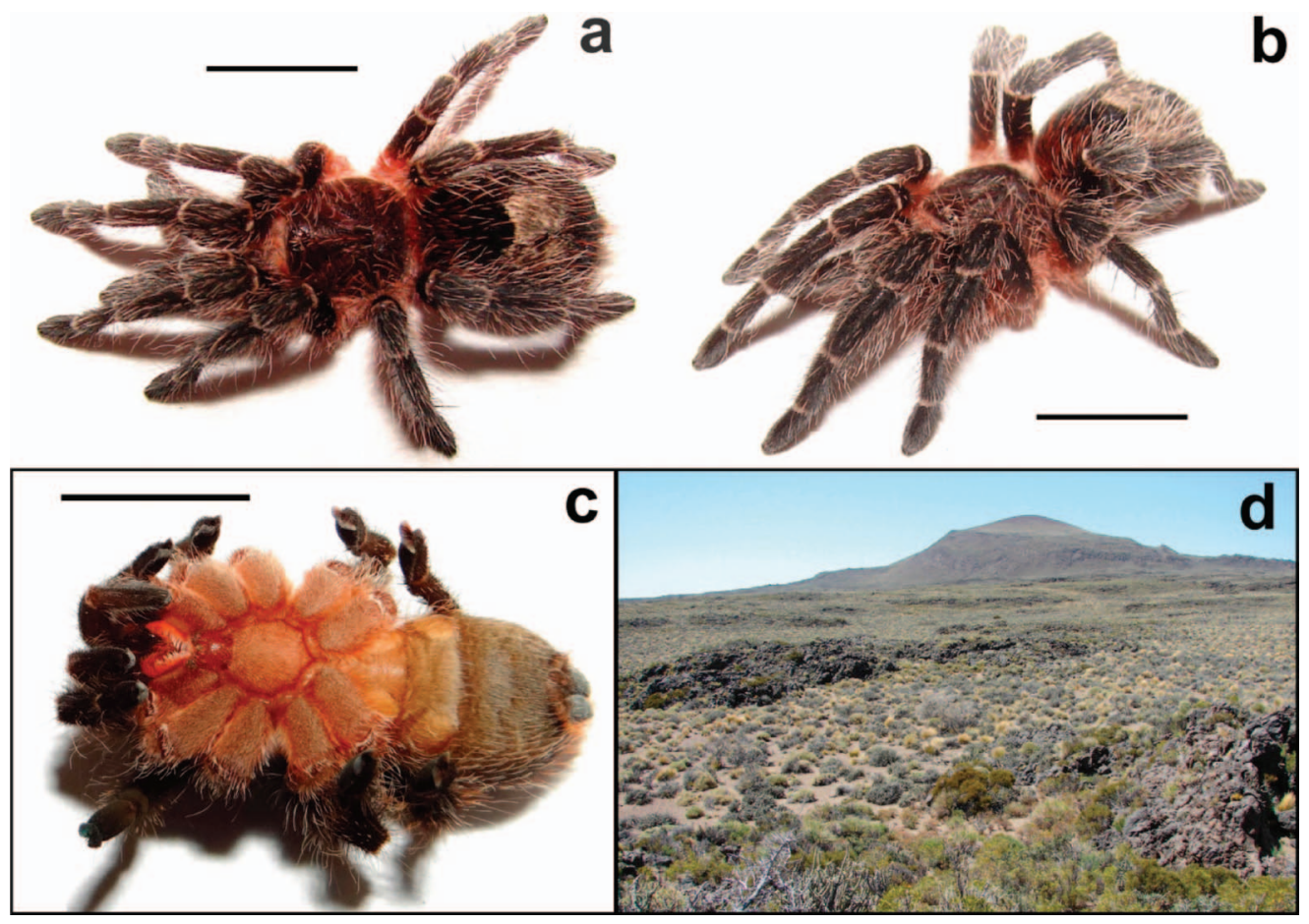

Figure 6.-Euathlus sagei sp. nov. female paratype (MACN-Ar 32686). a. a—c. Habitus; d. image depicting the habitat at the type locality. Scale bar $=1 \mathrm{~cm}$.

(MACN-Ar 32687). Female paratype: ARGENTINA: Neuquén: Ñorquin department, Copahue (37.7964 S, 71.1167 W), 25 March 2009, R. Sage (MACN-Ar 32688).

Etymology.-The specific name is "dark place" in Latin. Moreover, dark place corresponds to the meaning of "Curruhué" in Mapuche language, a dialect isolate spoken in south-central Chile and west-central Argentina by the Mapuche people. "Curruhué" is a name of a lake near to where this species was found.

Diagnosis.-Male differs from the other Euathlus species by a tibial apophysis with branches almost of equal sizes (Fig. 7e) and by an abruptly tapered bulb shape (Fig. 7a, b). Female differs from other Euathlus species by the shape of the spermathecae with two wide seminal receptacles with a lateral spheroid chamber not oriented apicolateral in opposition to the epigastric furrow (Fig. 8e). This species is characterized as inhabiting the Andean patagonic-forests with its reproductive period occurring in spring.

Description.-Male holotype (MACN-Ar 32687). Color (in alcohol): Cephalothorax with light grey small setae and golden

Table 6.-Euathlus tenebrarum sp. nov., length of leg and palpal segments of male.

\begin{tabular}{lccccc}
\hline & I & II & III & IV & Palp \\
\hline Femur & 8.4 & 7.3 & 7.2 & 7.7 & 4.4 \\
Patella & 4.1 & 4.2 & 3.5 & 4.4 & 3.2 \\
Tibia & 6.5 & 5.8 & 5.5 & 6.3 & 4.3 \\
Metatarsus & 6.1 & 6.6 & 6.4 & 7.6 & - \\
Tarsus & 4.1 & 4.2 & 4.3 & 5.2 & 2.2 \\
Total & 29.2 & 28.1 & 26.9 & 31.2 & 14.1 \\
\hline
\end{tabular}

long setae on margins and dorsal chelicerae; abdomen with a large patch of red setae on the anterior-dorsal face (Figs. 7c, d; 9a). Total length, not including chelicerae, nor spinnerets, 20.1. Carapace length 9.7, width 8.2. Anterior eye row procurved, posterior recurved. Eyes sizes and interdistances: AME 0.21, ALE 0.25, PME 0.14, PLE 0.21, AME-AME 0.28, AME-ALE 0.09, PME-PME 0.57, PME-PLE 0.08, ALEPLE 0.13, OQ length 0.8 , width 1.2 , clypeus 0.2 . Fovea transverse, slightly recurved, width 1.8. Labium length 0.6 , width 0.8 with 96 cuspules. Maxillae (right/left) with 118/120 cuspules. Sternum length 4.8, width 3.2 (Fig. 7d). Chelicerae with nine well-developed teeth on promargin of furrow and seven small teeth on retromargin. Tarsi I-IV densely scopulate and entire. Metatarsi I fully scopulate, II 1/2 scopulate, III 1/2, IV 1/3 apically scopulate. Leg and palpal segments lengths in Table 6. Spination: Femur IV and patellae of palp and legs I-IV, 0. Femora: palp 1 P; I 1 D; II 1 P; III 1 P. Tibiae: palp 11-2-1 P, $1 \mathrm{~V}$; I 2-1-2-1 V, 1-1 R, 2-1-2-1 P; II 1-1-2-1-2 V, 1 R, 2-1-1-1 P; III 1-1 V, 1-1-2-1 P, 1-1 R; IV 1-1-2 V, 1-2-1 P, 1-2-2 R. Metatarsi: I 0; II 2 V; III 1-2-2 V, 1-1 R, 1-2-1-1 P; IV 2-1-12 V, 1-1-1-1 P, 1-1-1 R. Tarsi I-IV, 0. Metatarsus I slightly

Table 7.-Euathlus tenebrarum sp. nov., length of leg and palpal segments of female.

\begin{tabular}{lcrrrr}
\hline & I & II & III & IV & Palp \\
\hline Femur & 7.3 & 6.8 & 5.4 & 7.7 & 5.6 \\
Patella & 4.4 & 4.3 & 3.5 & 4.4 & 3.0 \\
Tibia & 5.5 & 5.4 & 5.1 & 5.4 & 4.1 \\
Metatarsus & 4.3 & 4.2 & 5.0 & 7.5 & - \\
Tarsus & 2.9 & 3.6 & 3.5 & 4.3 & 3.3 \\
Total & 24.4 & 24.3 & 22.5 & 29.3 & 16.0 \\
\hline
\end{tabular}




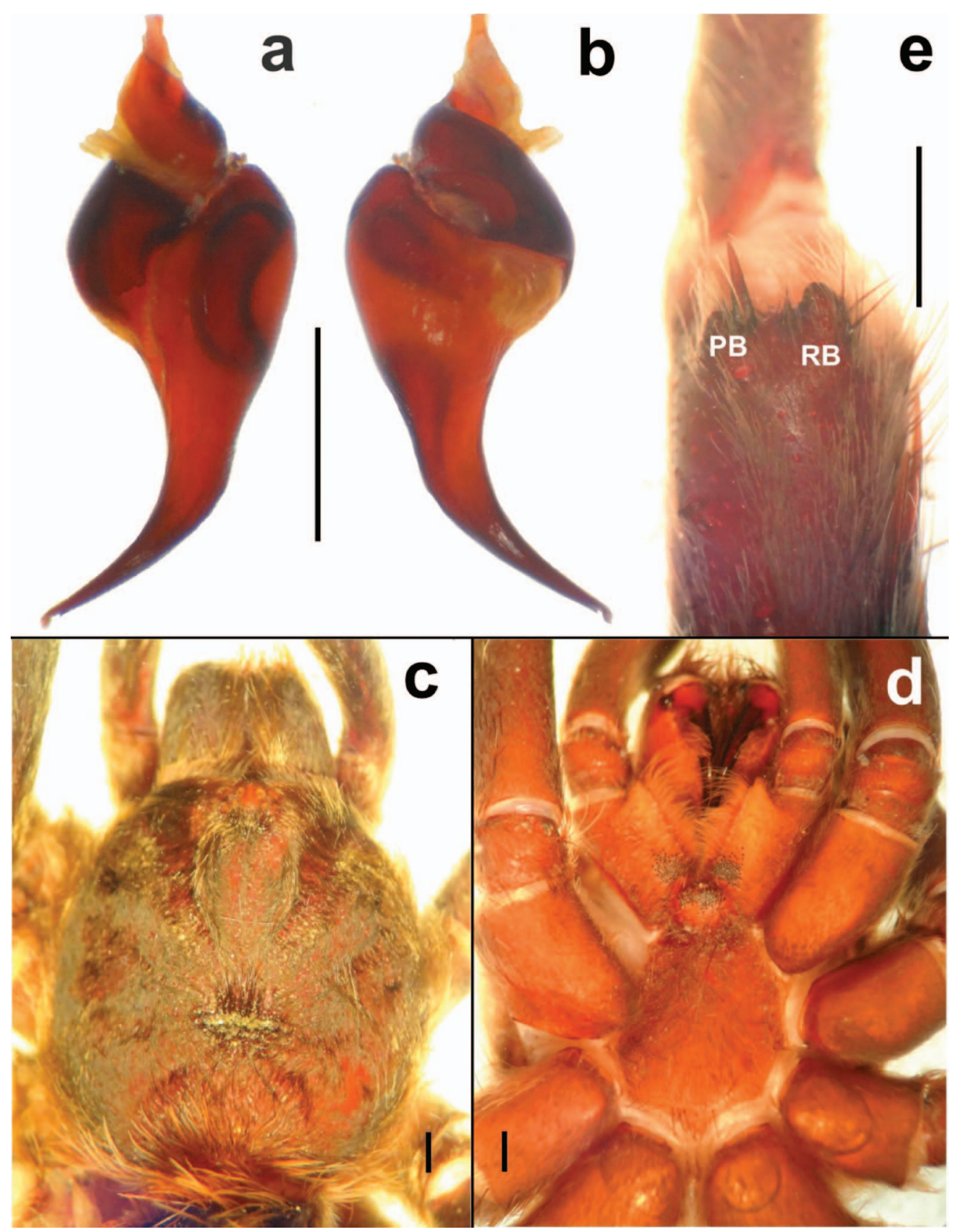

Figure 7.-Euathlus tenebrarum sp. nov. male holotype (MACN-Ar 32687). a. Palpal organ, prolateral view; b. palpal organ, retrolateral view; c. carapace, dorsal view; d. sternum, ventral view; e. tibial apophysis, ventral view. $\mathrm{PB}=$ prolateral branch, $\mathrm{RB}=$ retrolateral branch. $\mathrm{Scale}$ bar $=1 \mathrm{~mm}$.

curved. Tibia I possesses short apophyses with retrolateral branch slightly longer than prolateral; PB with an apical strong long spine, $\mathrm{RB}$ with an internal subapical short spine (Fig. 7e). Flexion of metatarsus I retrolateral to the tibial apophysis. Type III and IV urticating setae present. PMS well-developed, PLS normal, apical segment digitiform. Palpal organ abruptly tapering with flat and subequal less developed prolateral keels; flat PS long and closer to PI, and PI evidently truncated in the apical third of the embolus (Fig. 7a, b).

Female paratype (MACN-Ar 32688). Color (in alcohol): Carapace and legs brownish with patellar lines evident, abdomen brown (Fig. 8a, b). Brown setae on body mixed with golden setae. Total length, not including chelicerae, nor spinnerets, 23.6. Carapace length, 10.1, width 9.8. Anterior eye row procurved, posterior recurved. Eyes sizes and interdistances: AME 0.14, ALE 0.11, PME 0.16, PLE 0.12, AMEAME 0.29, AME-ALE 0.17, PME-PME 0.55, PME-PLE 0.06 , ALE-PLE 0.23, OQ length 0.9, width 1.2, clypeus 0.3. Fovea transverse, slightly recurved, width 1.1. Labium length 1.2 , width 1.4 with 68 cuspules. Maxillae (right/left) with 132/137 cuspules. Sternum length 4.6, width 3.9 (Fig. 8c). Chelicerae with seven well-developed teeth on promargin of furrow and six small teeth on the proximal area of furrow. 


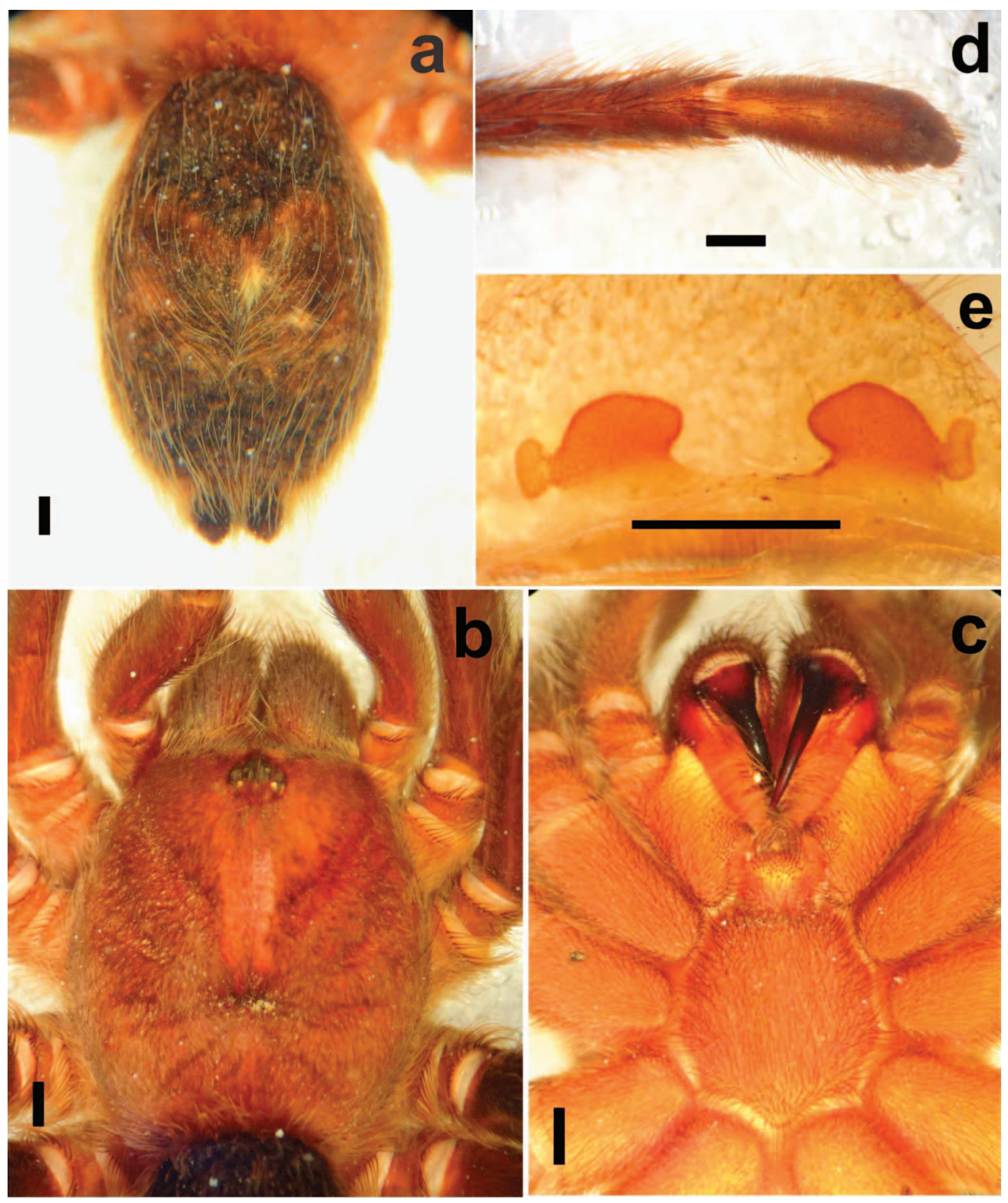

Figure 8.-Euathlus tenebrarum sp. nov. male holotype (MACN-Ar 32687). a. Abdomen, dorsal view; b. carapace, dorsal view; c. sternum, ventral view; d. tarsus IV, ventral view; e. spermathecae, dorsal view. Scale bar $=1 \mathrm{~mm}$.

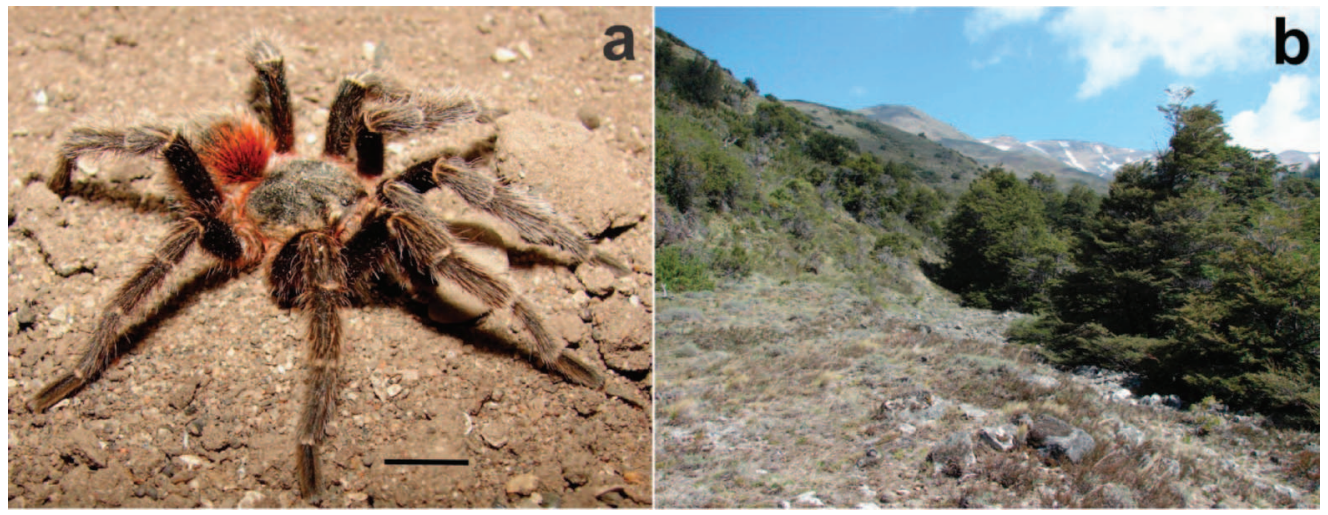

Figure 9.-Euathlus tenebrarum sp. nov. male holotype (MACN-Ar 32687). a. In life; b. image depicting the habitat at the type locality. Scale bar $=1 \mathrm{~cm}$ 


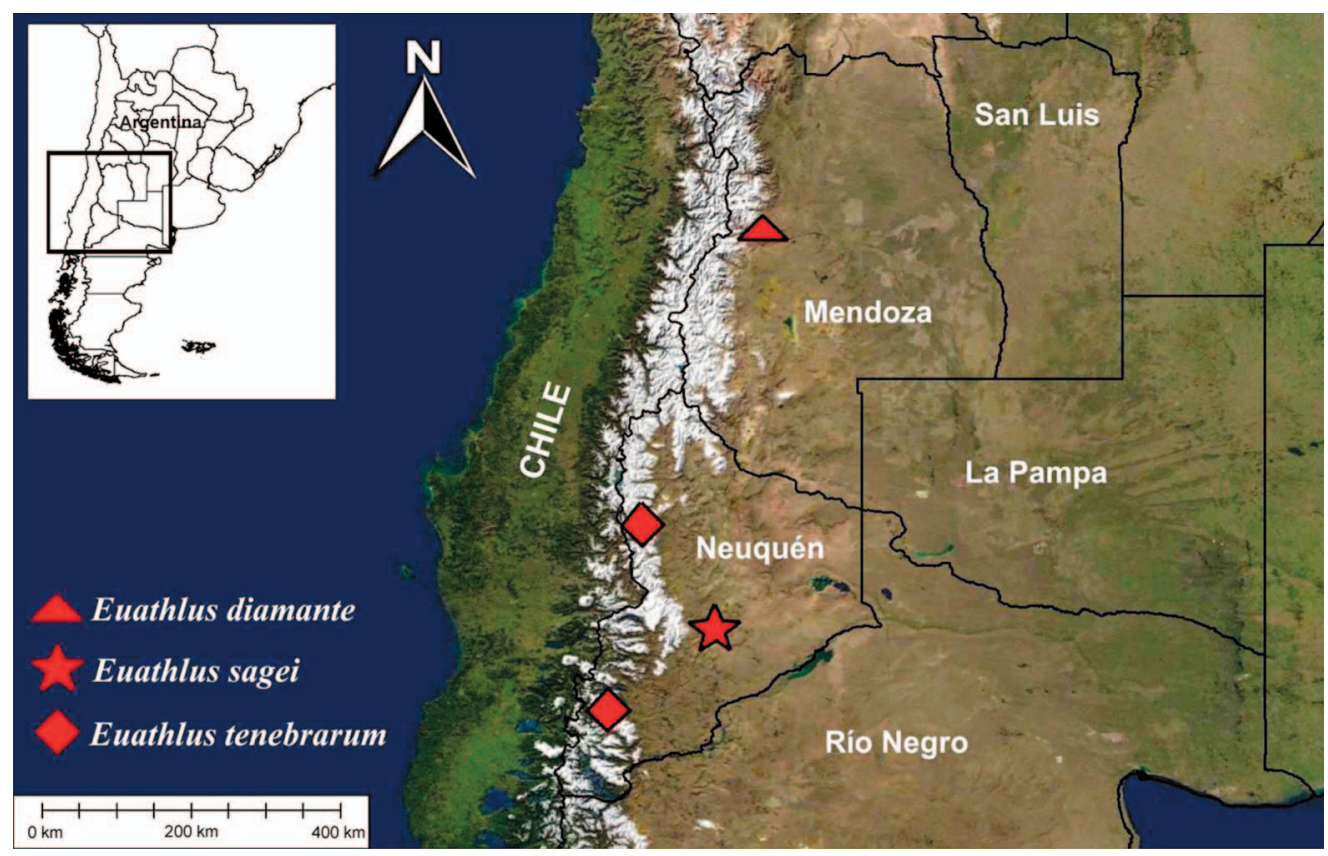

Figure 10.-Map showing the distribution of the Euathlus species treated in this work.

Tarsi I-III densely scopulate and entire, tarsus IV fully scopulate divided by a three-setal row. Metatarsi I fully scopulate divided by a row of single setae, II $1 / 2$ scopulate and divided by a row of single setae, III $1 / 3$ and divided by a row of paired setae, IV 1/4 apically scopulate and divided by a row of four setae (Fig. 8d). Leg and palpal segments lengths in Table 7. Spination: Femora I-III, patellae of palp and legs IIV and tarsi I-IV 0. Femur: IV 1 R. Tibiae: palp 1-1-2 V, 1-1-1 P, 1 R; I 1-2 V, 1 P; II 2 V, 1-1 P; III 1-2 V, 1-1-1-2 P, 1 R; IV 1-2 V, 1-1-1 P, 1-1-1 R. Metatarsi: I 1-1 V; II 1-1 V; III 1-1-1 V, 1-2-2 P, 1-2 R; IV 2-2-2 V, 1-1 P, 1-1-1-2 R. Type III and IV urticating setae present. PMS well-developed, PLS normal, apical segment digitiform. Spermathecae with two wide seminal receptacles with spheroid chamber pointing laterally (Fig. 8e).

Distribution and natural history.-Known from western Neuquén province, Argentina, at the Andean-patagonic forests (Fig. 10). The male holotype was found in October (spring in southern hemisphere) under a stone with no evident burrow or shelter, thus it was most likely wandering during this period. In this region the mean minimum temperature is $-2^{\circ} \mathrm{C}$ (July), the mean maximum is $23^{\circ} \mathrm{C}$ (January), and the mean annual temperature is $8^{\circ} \mathrm{C}$. Precipitation is concentrated mainly in autumn and winter, and it occurs as snow, with an annual rainfall of $1700 \mathrm{~mm}$ (Barros et al. 1983). At this latitude, mean precipitation decreases abruptly from about $4000 \mathrm{~mm} / \mathrm{year}$ on the western side of the Andes to less than $500 \mathrm{~mm} /$ year, only $80 \mathrm{~km}$ to the east (De Fina 1972). In the wetter area, the lowland rain forests are mainly dominated by the evergreen Nothofagus dombeyi (Mirb.) Oerst. (Nothofagaceae). In the intermediate parts of the precipitation gradient, at low elevations, $N$. dombeyi forms monospecific mesic forests or mixed stands of the conifer Austrocedrus chilensis (D. Don) Pic. Serm. \& Bizzarri
(Cupressaceae) at drier sites; in the eastern region, conifers shift to relatively open woodlands (Fig. 9b). In the western and central areas, forest understory is typically dominated by dense and tall $(>2 \mathrm{~m})$ populations of Chusquea culeou Desvaux (Poaceae) (Mermoz et al. 2005).

\section{DISCUSSION}

Euathlus was recently revised (Perafán \& Pérez-Miles 2014) and most species are recorded for Chile, with E. truculentus only recorded for Argentina in the province of Catamarca (north western Argentina) (Schiapelli \& Gerschman 1963). The descriptions of these three new species represent southern records for the genus in Argentina inhabiting very distinct habitats. The most geographically proximal species are $E$. truculentus and E. diamante sp. nov., the latter located more than $700 \mathrm{~km}$ south relative to E. truculentus. The other two new species are described from Neuquén province but inhabit different habitats. E. tenebrarum sp. nov. is located at high altitudes in Andean patagonic forests and E. sagei sp. nov. lives east of the Andean hills, in the extreme aridity of the patagonic steppe.

It is known that the Theraphosidae is a group that presents enormous morphological homogeneity and many taxonomic problems (Raven 1990; Bertani 2000) and many of the descriptions involve structures such as stridulatory organs, fovea shape, small differences in the proportions between leg articles and other body parts, size and disposition of the eyes and scopulae, and color patterns (Schiapelli \& Gerschman de Pikelin 1979; Raven 1985; Smith 1995; Prentice 1997). Many of these characters are conservative, but some new species were described based either on plesiomorphies or slight morphological variations (Bertani 2000). Although descriptions of these new species in the present work only refer to a single couple of specimens (holotype male and paratype 
female), the classification and identification is based mainly on genital structures, such as shape of spermathecae and palpal bulb features (mainly keels). These characters are conservative and in recent years have been shown in the Theraphosidae to be constant and useful in characterizing the taxa (Pérez-Miles et al. 1996; Bertani 2000, 2001; Perafán \& Pérez-Miles 2014). Moreover, as recently proposed by Ortiz \& Francke (2015), the male pedipalpal bulbs' structures are fundamental in Theraphosinae spiders' taxonomy as they are very often used as the cornerstone to differentiate between genera and species in the group. Also, other taxonomic characters such as extent of metatarsal scopulation and condition of tarsal scopula (entire or divided) were used and have been proven to have high discriminating value (Prentice 1997).

\section{ACKNOWLEDGMENTS}

The British Tarantula Society provided fund to the project during which the new species were collected. Special thanks are addressed to Susana Lagos Silnik and Cristian Grismado for lending some of the material from institutional collections. Richard Sage is thanked for providing some of the specimens studied in this work. Thanks to Gabriel Pompozzi, Sofía Copperi and Leonela Schwerdt for their help on field trips and photographs. Thanks to Alda González for her constant support on research experience. Administración de Parques Nacionales is thanked for giving necessary permits to carry out field studies at Nahuel-Huapi. The author is a researcher of Consejo Nacional de Investigaciones Científicas y Técnicas (CONICET).

\section{LITERATURE CITED}

Bertani, R. 2000. Male palpal bulbs and homologous features in Theraphosinae (Araneae, Theraphosidae). Journal of Arachnology 28:29-42.

Bertani, R. 2001. Revision, cladistics analysis, and zoogeography of Vitalius, Nhandu, and Proshapalopus; with notes on other Theraphosinae genera (Araneae: Theraphosidae). Arquivos de Zoologia 36:265-356.

Barros, V., V. Cordón, C. Moyano, R. Méndez, J. Forquera \& O. Pizzio. 1983. Cartas de Precipitación de la Zona Oeste de las Provincias de Río Negro y Neuquén, Primera Contribución, Facultad de Ciencias Agrarias, Universidad Nacional del Comahue, Neuquén, Argentina.

Bond, J.E. 2012. Phylogenetic treatment and taxonomic revision of the trapdoor spider genus Aptostichus Simon (Araneae, Mygalomorphae, Euctenizidae). Zookeys 252:1-209.

Cooke, J.A., V.D. Roth \& F. Miller. 1972. The urticating hairs of Theraphosidae. American Museum Novitates 2498:1-43.

Coyle, F.A. 1995. A revision of the funnel web mygalomorph spider subfamily Ischnothelinae (Araneae, Dipluridae). Bulletin of the American Museum of Natural History 226:1-133.

De Fina, A.L. 1972. El clima de la región de los bosques AndinoPatagónicos. Pp. 35-58. In La Región de Los Bosque AndinoPatagónico, Sinopsis General. (M. Dimitri, ed.). Instituto Nacional de Tecnología Agropecuaria (INTA), Buenos Aires.

Gandullo, R., P. Schmid \& O. Peña. 2011. Dinámica de la vegetación de los humedales del Parque Nacional Laguna Blanca (Neuquén, Argentina). Propuesta de un modelo de estados y transiciones. Multequina 20:43-62.
García-Cruz, J. \& V. Sosa. 2006. Coding quantitative character data for phylogenetic analysis: a comparison of five methods. Systematic Botany 31:302-309.

Goloboff, P.A. 1993. Estimating character weights during tree search. Cladistics 9:83-91.

Goloboff, P., J.S. Farris \& K.C. Nixon. 2003a. T.N.T: Tree Analysis Using New Technology. Online at http://www.zmuc.dk/public/ phylogeny

Goloboff, P., J. Farris, M. Källersjö, B. Oxelmann, M. Ramírez \& C. Szumik. 2003b. Improvements to resampling measures of group support. Cladistics 19:324-332.

Goloboff, P.A., C.I. Mattoni \& A.S. Quinteros. 2006. Continuous characters analyzed as such. Cladistics 22:589-601.

Hendrixson, B.E \& J.E. Bond. 2009. Evaluating the efficacy of continuous quantitative characters for reconstructing the phylogeny of a morphologically homogeneous spider taxon (Araneae, Mygalomorphae, Antrodiaetidae, Antrodiaetus). Molecular Phylogenetics and Evolution 53:300-313.

Mermoz, M., T. Kitzberger \& T.T. Veblen. 2005. Landscape influences on occurrence and spread of wildfires in Patagonia forest and shrublands. Ecology 86:2705-2715.

Ortiz, D. \& O.F. Francke. 2015. Two new species of Bonnetina tarantulas (Theraphosidae: Theraphosinae) from Mexico: contributions to morphological nomenclature and molecular characterization of types. Journal of Natural History 49:685-707.

Páez, M.M., F.A. Quintana \& C.F. Pérez. 2004. Biogeografía de las regiones áridas y semiáridas entre $35^{\circ}$ y $39^{\circ} \mathrm{S}$, Argentina. Boletín de la Sociedad Argentina de Botánica 39:171-180.

Page, R.D.M. 2001. Nexus Data Editor 0.5.0. Online at http:// taxonomy.zoology.gla.ac.uk/rod/rod.html

Perafán, C. \& F. Pérez-Miles. 2014. The Andean tarantulas Euathlus Ausserer, 1875, Paraphysa Simon, 1892 and Phrixotrichus Simon, 1889 (Araneae: Theraphosidae): phylogenetic analysis, genera redefinition and new species descriptions. Journal of Natural History 39-40:2389-2418.

Pérez-Miles, F., S.M. Lucas, P.I. da Silva Jr \& R. Bertani. 1996. Systematic revision and cladistic analysis of Theraphosinae (Araneae: Theraphosidae). Mygalomorph 1:33-68.

Pérez-Miles, F., R. Gabriel, L. Miglio, A. Bonaldo, R. Gallon \& J.J. Jiménez, et al. 2008. Ami, a new theraphosid genus from Central and South America, with the description of six new species (Araneae: Mygalomorphae). Zootaxa 1915:54-68.

Petrunkevitch, A. 1925. Arachnida from Panama. Transactions of the Connecticut Academy of Arts and Science 27:51-248.

Prentice, T.R. 1997. Theraphosidae of the Mojave desert west and north of the Colorado River (Araneae, Mygalomorphae, Theraphosidae). Journal of Arachnology 25:137-176.

Raven, R.J. 1985. The spider Infraorder Mygalomorphae (Araneae): cladistics and systematics. Bulletin of the American Museum of Natural History 182:1-180.

Raven, R.J. 1990. Comments on the proposed precedence of Aphonopelma Pocock, 1901 (Arachnida, Araneae) over Rhechostica Simon, 1892. Bulletin of Zoological Nomenclature 47:126.

Roig, F.A., E. Martínez Carretero \& E. Méndez. 1998. Mapa de vegetación de la Provincia de Mendoza, Programa Fitocartográfico Mendocino, Instituto Argentino de Investigaciones de las Zonas Áridas (IADIZA)-CRICYT, Mendoza, Argentina.

Schiapelli, R.D. \& B.S. Gerschman de P. 1963. Los géneros chilenos Phrixotrichus Simon, 1889 y Paraphysa Simon, 1892 (Theraphosidae, Araneae) en la Argentina. Nuevas citas de algunas arañas comunes a ambos países. Revista de la Sociedad Entomológica Argentina 26:103-108.

Schiapelli, R.D. \& B.S. Gerschman de Pikelín. 1979. Las arañas de la subfamilia Theraphosinae (Araneae, Theraphosidae). Revista del Museo Argentino de Ciencias Naturales Bernardino Rivadavia 5:287-330 
Smith, A.M. 1995. Tarantula Spiders: Tarantulas of the U.S.A. and Mexico. Fitzgerald Publishing, London.

Villamil, C.B. \& D. Testoni. 2012. Inventario Florístico Parque Nacional Laguna Blanca, Informe Convenio Específico $\mathrm{N}^{\circ} 481$. Universidad Nacional del Sur, Bahía Blanca, Argentina.
World Spider Catalog. 2014. Natural History Museum Bern. Online at http://wsc.nmbe.ch

Manuscript received 15 October 2014, revised 15 June 2015. 